\title{
W'INTERACÃO EM ET PSICOLOGIA
}

\section{Uma análise do livro "Deus um delírio" à luz do pensamento de Viktor Frankl}

\author{
Thiago Antonio Avellar de Aquino \\ Josilene Silva da Cruz \\ Erick Henrique da Costa Rodrigues
}

\section{RESUMO}

O ateísmo pode ser compreendido tanto como uma negação da existência de Deus como um conjunto de justificativas para sustentar esta proposição. Dessa forma, o presente artigo teve como objetivo identificar os diversos matizes de argumentos que refutam a existência de Deus no livro "Deus um delírio" de Richard Dawkins. Desenvolve-se numa perspectiva fenomenológica com o objetivo de tratar do ateísmo como objeto de estudo da Psicologia da Religião. Para tanto, foi utilizado o Método da Classificação Hierárquica Descendente (CHD) por meio do software IRAMUTEQ. Os resultados sugerem três classes de argumentos: por um lado, o científico-materialista, que se contrapõe ao Personalista, e teológico-moral. Os resultados foram analisados à luz da Análise Existencial de Viktor Frankl.

Palavras-chave: Ateísmo, Psicologia da Religião, Logoterapia.

\section{ABSTRACT}

Atheism may be understood as a denial of God's existence as well as a set of justifications for supporting this proposition. In this way, this article aims at identifying the various matrices of arguments that refute the existence of God in Richard Dawkins's book "The God Delusion". This study is based on a phenomenological perspective, and aims at apprehending the phenomenon of atheism as an object of study of the Psychology of Religion. Therefore, data were processed using IRAMUTEQ software and analyzed by the Descending Hierarchical Classification technique. Results suggest the presence of three classes of arguments: on the one hand, the materialistic scientist, which opposes the Personalist. On the other hand, the moral-theological argument. Results were analyzed from Viktor Frankl's Existential Analysis.

Keywords: Atheism, Psychology of Religion, Logotherapy.

O termo ateísmo, derivado do grego, significa ausência de deus ou deuses e se refere, de forma mais específica, à falta de crenças na existência de deidades (Bullivant, 2013). Por conseguinte, o ateísmo refuta os argumentos teístas na medida em que estes consideram as ideias antropomórficas como a base da religião e dividem a realidade em dois domínios, posto que a vida presente seria interpretada como uma preparação para uma vida futura. Nessa perspectiva, as crenças religiosas seriam consideradas como um produto da imaginação humana (Eucken, 1973). De forma geral, compreende-se que o ateísmo rejeita tanto a crença em Deus, como também refuta os argumentos em seu favor (Walters, 2015).

Como fenômeno humano referente ao sagrado, o ateísmo torna-se parte do estudo da Psicologia da Religião, posto que o objeto de estudo dessa área não se restringe apenas ao comportamento religioso, mas se detém, também, na apatia religiosa (Ávila, 2007). por exemplo, a concepção de Freud que compreendia a religião como um epifenômeno, tendo em conta que "o que emerge é um conjunto de 'impulsos do desejo' que mascaram a religião como algo de origem puramente humana, explicável somente em termos do natural desejo humano de proteção e felicidade" (Palmer, 2001, p.22).

Sigmund Freud fundamenta e exemplifica a religiosidade como um sentimento, o "sentimento oceânico". Em seus estudos, Freud analisa as possíveis facetas da religiosidade.

\section{Sobre os Autores}

T. A. A. A.

orcid.org/0000-0002-3903-8378 Universidade Federal da Paraíba (UFPB) - João Pessoa, PB logosvitae@hotmail.com

J.S. C.

orcid.org/0000-0001-5615-033X Universidade Federal da Paraíba (UFPB) - João Pessoa, PB josileneufpb@gmail.com

\section{E. H. C. R.}

orcid.org/0000-0003-0666-9867 Universidade Federal da Paraíba - João Pessoa, PB

erickenriquejj@hotmail.com

\section{Direitos Autorais}

Este é um artigo de acesso aberto e pode ser reproduzido livremente, distribuído,

transmitido ou modificado, por qualquer pessoa desde que usado sem fins comerciais. 0 trabalho é disponibilizado sob a licença Creative Commons CCBY-NC.

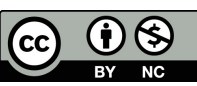




\section{W'INTERACÃO EM PSICOLOGIA}

O psicanalista propõe que a ausência da figura paterna e a superproteção materna, que é considerada uma falha, geram uma frustração na criança, e isso resultaria em um "sentimento oceânico", isto é, um sentimento de dimensão oceânica que implicaria na tentativa de a criança preencher as suas necessidades e singularidades durante sua vida (Freud, 2010).

Para Freud, esse sentimento oceânico estaria diretamente ligado à necessidade de sentido para a vida, visto que essa estrutura em forma de lacuna simbólica precisaria de um sentido estruturalmente compatível, grande; um símbolo de divindade onipotente tornar-se-ia em um viável candidato a preencher essa lacuna. Portanto, Freud analisa o sentimento oceânico de maneira experiencial, uma experiência de consolação que, em sua completude, proporciona ao sujeito um aspecto de uma unidade dele em relação à dimensão de seus símbolos (Freud, 2010).

Já para Comte-Sponville (2016, p.57), “o apego à esperança de uma outra vida que seria melhor, uma vida celestial, por um apego de viver o que há de certeza, uma eternidade de momentos chamado de presente". Ademais, segundo o mesmo autor, as religiões reúnem concepções para harmonizar questões existenciais, que, em sua grande maioria, se resumem envoltas aos problemas da finitude da vida e a dúvida de um possível "pós-vida", não obstante, conforme pensa, "a perspectiva de inferno é mais inquietante que a do nada" (Comte-Sponville, 2016, p. 16).

A apresentação de Sponville trabalha na posição em que aponta o homem para a unidade, que tem seu sentimento oceânico preenchido pela sensação experiencial proporcionada pela dimensão que o universo já possui: "Deus? Para quê? 0 universo basta. [...] 0 mundo basta. Uma fé? Para quê? A experiência basta." (Comte-Sponville, 2016, p. 141). Nessa perspectiva, o ateísmo encontra fundamento para não precisar acreditar que essa transcendência do uno seja um Deus, mas que seja simplesmente o absoluto da unidade do próprio universo em si. Nessa direção, Farias (2013) aventa que os ateus utilizariam as crenças naturalistas para aliviar a ansiedade, as dúvidas e o estresse, similar aos religiosos que utilizam seu sistema de crenças como um meio de enfrentamento.

Nessa esteira, Dawkins (2007) considera que as religiões promovem alívio para os aflitos e argumenta que "falsas crenças podem ser tão reconfortantes quanto as verdadeiras [...]" (Dawkins, 2007, p. 450). O sucesso desses conceitos parece refletir em um possível benefício histórico-social, como propôs Richard Dawkins (2007). Dessa forma, a promoção de declarações como: "você sobreviverá a própria morte" e "a crença em Deus é uma virtude suprema [...]" tem conquistado um grupo de indivíduos sujeitos à completude que essas afirmações podem proporcionar, condição satisfatoriamente advinda da fuga em relação aos medos das questões misteriosas da vida (Dawkins, 2007, p. 263). 0 autor em tela assevera que a crença em uma divindade é infundada e assemelha-se a um delírio, uma vez que a percepção valorativa e construção moral do sujeito não dependeriam especificamente de uma religião. Postula ainda gradações, ou marcadores entre a crença e descrença em Deus, a partir das possibilidades de sua existência que pode variar entre os extremos teístas convictos (aqueles que sabem da existência de Deus) e o ateu convicto (aquele que assume saber da inexistência de Deus), tendo como ponto intermediário o agnóstico.

\section{SENTIDO DE VIDA E (A)TEISMO}

A logoterapia e Análise Existencial de Viktor Frankl compreende a religião como um fenômeno humano. Nessa acepção, o autor investiga o lugar que a religiosidade ocupa na vida da pessoa (Frankl, 2000) sem negar nem afirmar a realidade ontológica do Transcendente, pois trata a religiosidade como sendo um objeto e não um posicionamento (Frankl, 1999). Dessa forma, considera-se um equívoco asseverar que o autor defenda uma psicologia da religião a serviço do religioso como o fez Belzen (2013).

Em oposição a Dawkins (2007), que considera que a pergunta acerca do propósito, ou do sentido seria ilegítima, Frankl (2010) advoga a busca de sentido como sendo a motivação primária e genuína do ser humano, constituindo-se um fator relevante para a saúde e sobrevivência do ser humano. Frankl aborda a questão do teísmo e do ateísmo a partir da dimensão do espírito humano. Na concepção frankliana, a dimensão noológica, a qual abarca os fenômenos especificamente humanos, a exemplo da liberdade e da responsabilidade, bem como se encontra a "liberdade espiritual do ser humano, a qual não se the pode tirar, permite-lhe, até o último suspiro, configurar sua vida de modo que tenha sentido" (Frankl, 2010 p. 89).

Destarte, torna-se necessário esclarecer que o fenômeno da espiritualidade não está necessariamente vinculando aos aspectos da religiosidade, pois a espiritualidade consiste numa instância muito maior do que a própria experiência religiosa, tendo em conta que "a espiritualidade, seja laica ou religiosa, ateia ou teísta, panteísta ou politeísta, horizontal ou vertical, é uma riqueza do ser humano que não se pode subestimar" (Torralba, 2013, p. 57).

Frankl considera a religião como uma vontade de sentido último, embora advogue que todo ser humano procura, em última instância, um sentido para a vida, seja ele religioso ou não. A fé religiosa não é um ato volitivo, pois como todo fenômeno intencional, requer um conteúdo adequado (Frankl, 


\section{W'INTERACÃO EM E. PSICOLOGIA}

Thiago Antônio Avellar de Aquino, Josilene Silva Cruz e Erick Henrique da Costa Rodrigues

\section{5). Assim expressa o autor:}

Acreditar não depende do querer; esperar não depende do querer; amar não depende do querer; e acima de tudo, querer não depende do querer. Tentativas de fazer isso refletem uma imposição inteiramente manipulativa de fenômenos humanos tais como a fé, a esperança, o amor e a vontade (Frankl, 1989, p. 69).

Outrossim, pode-se compreender que o ateu seria aquele a quem foi apresentado um conteúdo religioso inadequado, coo a visão de um Deus mesquinho, quando intenciona que um maior número de pessoas acreditem nele apenas por meio de uma determinada perspectiva religiosa (Frankl, 1995). O referido autor faz uma distinção entre a forma de confissões religiosas e a meta das religiões: "Quanto mais se busca a meta, menos o caminho é discutido e se vê este unicamente como um caminho para uma meta" (Frankl, 2003, p. 294). Quando se fixa apenas em um único caminho, podese levar a uma rigidez religiosa e, por conseguinte, ao fanatismo. Quando se detém na meta, pode-se promover a tolerância entre os credos religiosos. Conforme o autor: "Quem não se mantém firme na fé se aferra fortemente ao dogma rígido; quem está firme na fé tem mãos livres e as estende aos demais para estar em comunicação existencial com eles" (Frankl, 2003, 294-295).

Nessa esteira, o homo religiosus deveria ter mais tolerância com a escolha do ser humano não religioso, respeitando a liberdade de escolha do ateu, posto que é a própria cosmologia religiosa que pressupõe a pessoa dotada de liberdade. Partindo dessa premissa, essa mesma liberdade também permite ao homem rejeitar qualquer Weltanschauung religiosa (Frankl, 1999). Por outro lado, Frankl (1995), como médico, presenciou a morte de ateus convictos, e relatou um sentimento religioso em pessoas não religiosas:

(...) no seu leito de morte, 'na hora suprema', deram testemunho do que nunca, durante décadas, teria sido capaz de antecipar a ninguém, a saber, uma sensação de segurança, de descanso sereno, que não só contraria a sua ideologia do passado, como também não pode tão pouco ser intelectualizada ou racionalizada. (Frankl, 1995, 93-94).

Dessa forma, numa perspectiva fenomenológica, a diferença entre ateu e homem religioso estaria justamente na forma de interpretar a voz da consciência (Gewissen). Para o primeiro, a consciência é a última instância, perante quem ele se sente responsável. Já o segundo, interpreta que a consciência transcende para o suprassentido (Übersinn), questão existencial a quem ele deve ser servo (Frankl, 1995). Especificamente quanto ao homem ateu, Frankl e Lapide
(2005) identificam quatro grupos de ateus de acordo com os argumentos referentes aos sistemas religiosos:

1) Aspecto anticlerical: argumentos que levam em consideração que, por um lado, há uma revolta contra sacerdotes e os representantes de Deus, por outro lado, expressam uma culpa em relação a Deus pelos erros dos seus seguidores;

2) Aspecto infantil: justificativas que se posicionam contrárias às imagens infantilizadas que receberam na tenra idade, as quais não preenchem a genuína necessidade de fé;

3) Aspecto do ressentimento: raciocínios que consideram que os ateus não perdoaram o mal existente no mundo;

4) Aspecto moral: alegações que sugerem não aceitar a moral prescritiva da qual o ser humano deveria ser bom para merecer ir para o céu, pois argumentam que o bem seja um fim em si mesmo.

Tendo em conta que há um matiz de argumentos que refutam a existência de Deus, o objetivo do presente trabalho foi analisar o livro "Deus, um delírio" de Richard Dawkins (2007), à luz do pensamento de Viktor Frankl. O trabalho se justifica na medida em que esse autor é um dos principais representantes contemporâneos do ateísmo, o que o torna um objeto plausível entre os estudos sobre religião nos tempos atuais.

\section{MÉTODO}

Esta pesquisa fundamentou-se na análise textual por meio do software Iramuteq. De acordo com Camargo \& Justo (2013), esse software desenvolvido pelo francês Pierre Ratinaud, em 2009, vem sendo utilizado em pesquisas no Brasil desde 2013. Neste estudo, procedeu-se ao método de Classificação Hierárquica Descendente (CHD), tendo como corpus o livro "Deus, um delírio". Essa análise permitiu à identificação de classes semânticas desse corpus em segmentos de texto mediante o vocabulário, formando conjuntos de palavras lematizadas e aproximadas pelo seu significado, bem como demonstrou seus percentuais dentro do corpus analisado.

\section{RESULTADOS}

Inicialmente o corpus do livro "Deus, um delírio" foi dividido em 3662 segmentos de texto, e 90,03\% desses segmentos foram considerados pelos pesquisadores na análise. Por meio do método de Classificação Hierárquica Descendente (CHD), constatou-se a presença de três classes lexicais distintas. Tais classes foram obtidas a partir dos segmentos de textos que compartilharam o vocabulário de 


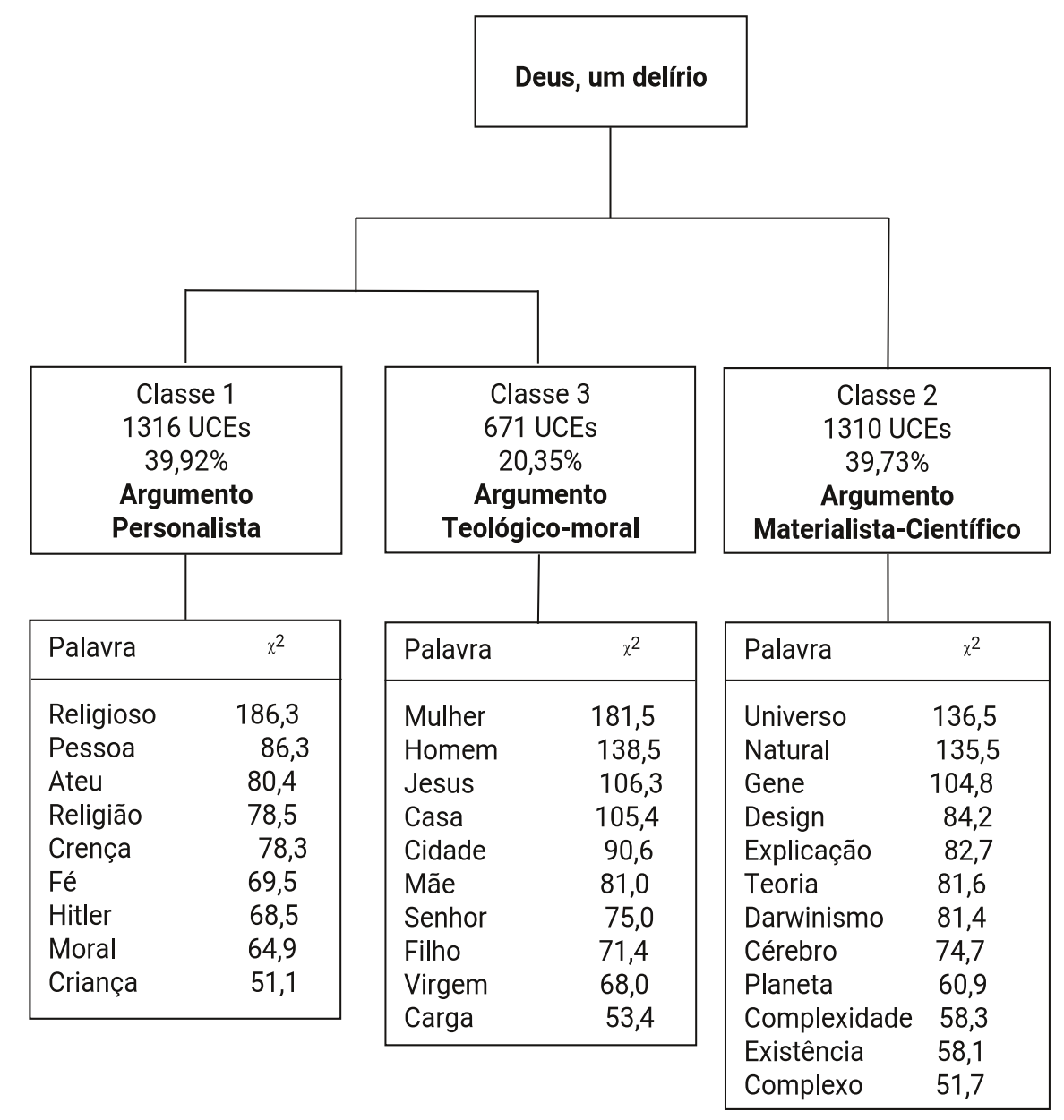

Figura 1. Dendograma da análise textual do livro “Deus, um delírio” pelo Método de Classificação Hierárquica

Richard Dawkins, conforme apresenta o dendograma na Figura 1.

A Classe 1 foi constituída por 1316 Unidades de Contexto Elementares (UCE), representando 39,9\%. As principais palavras que se associaram a essa classe foram: religioso, pessoa, ateu, religião, crença, fé, Hitler, entre outros. O conjunto de segmentos de palavras pode ser semanticamente denominado de Argumento Personalista. São exemplos dessa classe:

Mas Hitler nunca renunciou formalmente ao catolicismo e existem indicações ao longo da vida dele que tenha permanecido religioso, se não católico, ele parece ter ficado com a crença em algum tipo de providência divina (Dawkins, 2007, p. 283).

Há algo infantil na ideia de que outra pessoa, pais no caso de crianças, deus no caso de adultos, tem responsabilidade de dar sentido e objetivo a sua vida (Dawkins, 2007, p. 365).
Alguns ateus são felizes, outros são desgraçados; do mesmo jeito, alguns cristãos, mulçumanos hindus e budistas são uns desgraçados enquanto outros são felizes (Dawkins, 2007, p. 357-358).

Já a Classe 2 abarcou 1310 Unidades de Contexto Elementares (UCE), representando $39,73 \%$. Os principais elementos relacionados a essa classe foram: universo, natural, gene, design, explicação, teoria, darwinismo, dentre outros. O conjunto de segmentos de palavras pode ser semanticamente denominado de Argumento Materialistacientífico. São exemplos dessa classe:

O que a maioria dos ateus acredita é que embora só haja um tipo de matéria no universo, e é a matéria física, dessa matéria nascem a mente, a beleza, as emoções, os valores morais, em suma, a gama completa de fenômenos que enriquecem a vida humana (Dawkins, 2007, p. 28).

Se houver alguma coisa que pareça estar além do mundo 


\section{N"INTERACÃO EM PSICOLOGIA}

natural, conforme o entendemos hoje, esperamos no fim ser capazes de entendê-la e adotá-la dentro da natureza (Dawkins, 2007, p. 28).

Sabendo que somos produtos da evolução darwinista, devemos perguntar que pressão ou pressões exercidas pela evolução natural favorecem ao impulso, à religião (Dawkins, 2007, p. 173).

Por fim, a Classe 3 reuniu 671 Unidades de Contexto Elementares (UCE), representando 20,35\%. Os principais elementos que emergiram nessa classe foram: mulher, homem, Jesus, casa, cidade, mãe, dentre outros. 0 conjunto de segmentos de palavras pode ser semanticamente denominado de Argumento Teológico-moral. Constituem exemplos dessa classe:

Até mesmo resistir a um estupro poderia ser representado como assassinar um bebê em potencial e, aliás, há um monte de ativistas pró-vida que negariam o aborto até a mulheres vítimas de estupros brutais (Dawkins, 2007, p. 309).

Teólogos mais sofisticados declaram que deus não tem sexo, embora alguns teólogos feministas queiram compensar injustiças históricas. Mas, afinal de contas, qual é a diferença entre uma mulher inexistente e um homem inexistente? (Dawkins, 2007, p. 48).

Afirmar que como Jesus alegava ser o filho de deus ou ele estava certo ou ele estava louco (Dawkins, 2007, p. 104).

\section{DISCUSSÃO}

De forma geral, conforme se pôde constatar por meio do dendograma (Figura 1), todo o discurso de Richard Dawkins é baseado na contraposição de juízos científico-materialistas, por um lado, e argumentos personalistas e teológico-morais, por outro. Ademais, pôde-se constatar uma aproximação dos seus argumentos com a tipologia proposta por Frankl e Lapide (2005). Nessa perspectiva, observam-se argumentos referentes aos aspectos do ressentimento, sobretudo, referindo-se a Hitler como não tendo abandonado o seu senso religioso, bem como do anticlericalismo, na medida em que o ateísmo considera que ser religioso, ou não, não é uma garantia para a felicidade.

0 aspecto infantil pode ser constatado ao argumentar que na perspectiva do homem religioso o propósito da vida é dado por Deus, retirando a responsabilidade pessoal. Nessa concepção, Frankl (2003) assevera que não seria Deus que estaria morto, mas a imagem infantilizada de Deus derivada de um condicionamento sociológico. Embora a análise existencial do homem religioso descreva Deus com a imagem do contramestre que fornece sentido à vida (Frankl, 2010), para esse autor, independentemente de ser religioso ou não, o ser humano encontra sentido na vida a partir de sua liberdade da vontade. No caso do homem religioso, mediante as escolhas na sua existência, ele se sentiria responsável não apenas diante da sua consciência, mas também perante o seu Deus (Aquino, 2014; Frankl, 2010).

No aspecto moral, Dawkins (2007) argumenta que os religiosos não permitem o aborto em caso de estupro. Entretanto, o argumento não sugere uma preocupação em ser bom para merecer uma vida no pós-morte, mas se restringe a uma busca do próprio bem-estar já que rejeita a possibilidade de uma dimensão supraterrestre. Para Frankl (1999), o ser humano deveria consultar a sua consciência valorativa para resolver conflitos morais, dessa forma, não se poderia transformar um valor em um meio para um fim, seja para obter uma consciência tranquila ou obter uma recompensa após a morte.

Sobre a divindade de Jesus, Dawkins (2007) considera duas possibilidades: "ou ele estava certo ou ele estava louco". De fato, há apenas uma verdade, mas não se pode afirmar quem a detém (Frankl, 1999), da mesma forma, compreendese que não é possível estabelecer com quem estaria a verdade, com os religiosos ou com os ateus. Assim, poderia resultar em uma postura de maior tolerância entre os dois grupos (teísta e ateísta). Ademais, em sua obra, Frankl (2003) alerta para o perigo do reducionismo quando aponta que Joana Darc teria sido reduzida a "nada mais que" uma esquizofrênica, renegando todo o seu valor histórico, alertando que os personagens religiosos não podem ser compreendidos como meros epifenômenos a uma psicopatologia, renegando a sua dimensão saudável, posto que $2 \times 2=4$, mesmo que seja dito por um esquizofrênico (Frankl, 1992).

Observa-se também que a classe 2 representa o ponto de partida da cosmovisão de Dawkins (2007), já que se fundamenta nos argumentos materialista-científicos, logo, para o autor, a matéria é a origem e a explicação de todos os fenômenos e nada estaria fora do mundo natural. Não obstante, Frankl (2003) assevera que é impossível abarcar os fenômenos em sua totalidade, pois estão além da apreensão e compreensão racional, ademais, o sentido do todo não é passivel de demonstração, pois não compartilharia a dimensão sensível tal como os fenômenos naturais.

"A ciência natural apenas chega a tomar notas dos acontecimentos. 0 perguntar pelo sentido, o dar sentido ao acontecer natural, não é sua competência" (Frankl, 2003, p. 152). Para o ateísmo, cabe o ônus da prova (onus probandi) e, assim, advogar pela inexistência de Deus. Já para o homem religioso não cabe a dúvida, mas suportar a sua 


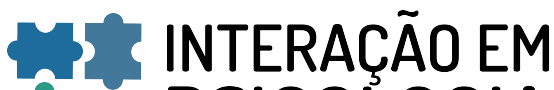 PSICOLOGIA}

Thiago Antônio Avellar de Aquino, Josilene Silva Cruz e Erick Henrique da Costa Rodrigues indemonstrabilidade, limitando-se ao seguinte argumento probabilístico: "a maior parte das realidades têm sentido; um sentido concreto. Por isso, a crença de que tudo tem sentido é provavelmente racional" (Frankl, 2003, p. 246-247). Dessa forma, a ciência natural não seria suficiente para explicar a adesão ao sistema de pensamento religioso, posto que a vontade de um sentido último estaria em uma dimensão de uma categoria transcendental, ou seja, em uma dimensão racional.

Por fim, compreende-se, à luz do pensamento de Viktor Frankl, que o ateísmo seria a comprovação cabal da liberdade da vontade, já que o ser humano seria o único ser que, em última instância, escolheria entre crer ou não crer em um Deus transcendente. Assim, teístas e ateístas estariam unidos por uma qualidade espiritual comum: a liberdade da escolha.

\section{CONSIDERAÇÕES FINAIS}

O objetivo do estudo, em analisar o livro "Deus, um delírio", de Richard Dawkins (2007), à luz do pensamento de Viktor Frankl, foi plenamente alcançado por meio da identificação das classes que compõem os argumentos ateístas desse autor. Embora Frankl e Dawkins não tenham se encontrado para promover um diálogo, o presente artigo proporcionou um debate entre esses dois pensadores do século $X X$ que ainda repercutem no campo do conhecimento nos dias atuais. Esse confronto pode ser profícuo para o campo científico para ampliar o horizonte dos tipos de argumentos que constituem o ateísmo moderno. Assim, recomenda-se que novos olhares possam se debruçar sobre a obra de Dawkins, com o escopo de proporcionar novas propostas acerca dos argumentos e provocações científicas para o campo da Psicologia da Religião.

\section{DECLARAÇÃO DE FINANCIAMENTO}

A pesquisa relatada no manuscrito foi financiada parcialmente pela bolsa de doutorado da segunda autora.

\section{CONTRIBUIÇÃO DOS AUTORES}

T. A. A. A. contribuiu para a conceitualização da logoterapia e análise existencial, investigação e visualização do artigo; J. S. C. descrição metodológica e resultados e E. H. C. R. foi o responsável pela visão do ateísmo.

\section{DECLARAÇÃO DE CONFLITOS DE INTERESSE}

Os autores declaram que não há conflitos de interesse no manuscrito submetido.

\section{REFERÊNCIAS}

Aquino, T. A. A. (2014). A presença não ignorada de Deus na obra de Viktor Frankl: Articulações entre logoterapia e religião. São Paulo: Paulus

Ávila, A. (2007). Para conhecer a psicologia da religião. São Paulo: Loyola.

Belzen, J. (2013). Constituição histórica da psicologia científica da religião. In Usarski, F \& Passos, J. D. (Orgs). Compêndio de Ciência da Religião (pp. 319-331). São Paulo: Paulinas/ Paulus.

Bullivant, S. (2013). Defining atheism. In Bullivant, S. \& Ruse, M. (Eds.), The Oxford Handbook of Atheism (pp. 11-21). Oxford, England: Oxford University Press.

Camargo, B. V., \& Justo, A. M. (2013). IRAMUTEQ: Um Software Gratuito para análise de Dados Textuais. In Temas em Psicologia, 21(2)513-518.

Comte-Sponville, A. (2016). o espírito do ateísmo: introdução a uma espiritualidade sem Deus. Martins Fontes: São Paulo.

Dawkins, R. (2007). Deus, um delírio. São Paulo: Companhia das Letras.

Eucken, R. (1973). Sentido e o valor da vida. Rio de Janeiro: Opera Mundo.

Farias, M. (2013). The psychology of atheism. In Bullivant, S. \& Ruse, M. (Eds). The handbook of Atheism (pp. 468-482). Oxford, England: Oxford University Press.

Frankl, V. E. (1989). Um sentido para a vida: Psicoterapia e humanismo. Aparecida (SP): Editora Santuário.

Frankl, V. E. (1992) Psicoanalisis y existencialismo: de la psicoterapia a la logoterapia. México (DF): Fondo de Cultura Enonómica.

Frankl, V. E. (1995). La presencia ignorada de Dios: psicoterapia y religion. Barcelona: Herder.

Frankl, V. E. (1999). El hombre em busca del sentido último: el análisis existencial y la consciencia enpiritual del ser humano. Barcelona: Paidos.

Frankl, V. E. (2000). Em el principio era el sentido: Reflexiones em torno al ser humano. Espanha: Paidós.

Frankl, V. (2003). El hombre doliente: fundamentos antropológicos de la psicoterapia. Barcelona: Herder.

Frankl, V. (2010). Em busca de sentido: Um Psicólogo no campo de concentração. Vozes/Sinodal: Petrópolis.

Frankl, V. \& Lapide, P. (2005). Búsqueda de Dios y sentido de la vida: Diálogo entre um teólogo y um psicólogo. Barcelona: Herder. 
Freud. S. (2010 [1930]). O mal-estar na civilização. In Sigmund Freud (Ed.), Obras completas (Vol. 18). São Paulo: Companhia das letras. (J. Salomão, Trad.).

Palmers, M. (2001). Freud e Jung: sobre a religião. São Paulo: Edições Loyola.

Torralba, F. R. (2013). Inteligência espiritual. Petrópolis, RJ: Vozes.
Walters, K. (2015) Ateísmo: um guia para crentes e não crentes. São Paulo: Paulinas.

Recebido em 19/02/2019 Primeira Decisão Editorial em 29/04/2019 Aceito em 01/05/2019 